\title{
A Serum Protein Biomarker Panel Improves Outcome Prediction in Human Traumatic Brain Injury
}

\author{
Eric Thelin, ${ }^{1-3,{ }^{*}}$ Faiez Al Nimer, ${ }^{1,2, *}$ Arvid Frostell, ${ }^{1}$ Henrik Zetterberg, ${ }^{4-7}$ Kaj Blennow, ${ }^{4,5}$ Harriet Nyström, ${ }^{1,8}$ \\ Mikael Svensson, ${ }^{1,9}$ Bo-Michael Bellander, ${ }^{1,9}$ Fredrik Piehl, ${ }^{1,2}$ and David W. Nelson ${ }^{10}$
}

\begin{abstract}
Brain-enriched protein biomarkers of tissue fate are being introduced clinically to aid in traumatic brain injury (TBI) management. The aim of this study was to determine how concentrations of six different protein biomarkers, measured in samples collected during the first weeks after TBI, relate to injury severity and outcome. We included neurocritical care TBI patients that were prospectively enrolled from 2007 to 2013, all having one to three blood samples drawn during the first 2 weeks. The biomarkers analyzed were S100 calcium-binding protein B (S100B), neuron-specific enolase (NSE), glial fibrillary acidic protein (GFAP), ubiquitin carboxy-terminal hydrolase-L1 (UCH-L1), tau, and neurofilament-light (NF-L). Glasgow Outcome Score (GOS) was assessed at 12 months. In total, 172 patients were included. All serum markers were associated with injury severity as classified on computed tomography scans at admission. Almost all biomarkers outperformed other known outcome predictors with higher levels the first 5 days, correlating with unfavorable outcomes, and UCH-L1 (0.260, pseduo- $\left.R^{2}\right)$ displaying the best discrimination in univariate analyses. After adjusting for acknowledged TBI outcome predictors, GFAP and NF-L added most independent information to predict favorable/unfavorable GOS, improving the model from 0.38 to 0.51 pseudo- $R^{2}$. A correlation matrix indicated substantial covariance, with the strongest correlation between UCH-L1, GFAP, and tau $(r=0.827-0.880)$. Additionally, the principal component analysis exhibited clustering of UCH-L1 and tau, as well as GFAP, S100B, and NSE, which was separate from NF-L. In summary, a panel of several different protein biomarkers, all associated with injury severity, with different cellular origin and temporal trajectories, improve outcome prediction models.
\end{abstract}

Keywords: functional outcome; injury severity assessment; neuroradiology; protein biomarkers; serum analysis; traumatic brain injury

\section{Introduction}

$\mathbf{T}$ Traumatic Brain InJURY (TBI) is a devastating disease and one of the most common reasons people are living with acquired disabilities, ${ }^{1}$ leading to increasing suffering and societal costs. TBI usually results in a combination of diffuse tissue injuries and a spectrum of focal lesions, as well as a range of subsequent secondary injury responses, making TBI a biologically very complex and heterogenic condition. ${ }^{2}$ Analyzing admission parameters have improved outcome prediction in $\mathrm{TBI},{ }^{3,4}$ which may provide tools for resource allocation both on the group level, but also on individual treatment strategies. However, the performance of

\footnotetext{
${ }^{1}$ Department of Clinical Neuroscience, Karolinska Institutet, Stockholm, Sweden.

${ }^{2}$ Department of Neurology, Karolinska University Hospital, Stockholm, Sweden.

${ }^{3}$ Division of Neurosurgery, Department of Clinical Neurosciences, University of Cambridge, Cambridge, United Kingdom.

${ }^{4}$ Clinical Neurochemistry Laboratory, Sahlgrenska University Hospital, Mölndal, Sweden.

${ }^{5}$ Department of Psychiatry and Neurochemistry, Institute of Neuroscience and Physiology, the Sahlgrenska Academy at the University of Gothenburg, Mölndal, Sweden.

${ }^{6}$ Department of Neurodegenerative Disease, UCL Institute of Neurology, Queen Square, London, United Kingdom.

${ }^{7}$ UK Dementia Research Institute, UCL, London, United Kingdom.

${ }^{8}$ Department of Neuroradiology, Karolinska University Hospital, Stockholm, Sweden.

${ }^{9}$ Department of Neurosurgery, Karolinska University Hospital, Stockholm, Sweden.

${ }^{10}$ Department of Physiology and Pharmacology, Section of Perioperative Medicine and Intensive Care, Karolinska Institutet, Stockholm, Sweden.

*These authors contributed equally.

(C) Eric Thelin et al., 2019; Published by Mary Ann Liebert, Inc. This Open Access article is distributed under the terms of the Creative Commons License (http://creativecommons.org/licenses/by/4.0), which permits unrestricted use, distribution, and reproduction in any medium, provided the original work is properly credited.
} 
current prediction models is limited and much variance remains unexplained. ${ }^{5,6}$

Serum brain-enriched proteins of tissue fate are increasingly used as biomarkers to manage TBI patients. ${ }^{7}$ For example, serum S100 calcium-binding protein B (S100B) is part of the Scandinavian neurotrauma guidelines to reduce the number of unnecessary computerized tomography (CT) scans in mild TBI patients. ${ }^{8}$ Biomarkers may also be used to monitor emerging secondary injury processes, as well as to improve outcome prediction..$^{9-11}$ Whereas these biomarkers are often used as single variables, by analyzing several proteins, with different cellular origins, it may be possible to delineate distinct pathophysiological processes in the injured brain, ${ }^{12}$ which, in turn, could result in more-precise outcome predictions.

The most well-studied protein in TBI is $\mathrm{S} 100 \mathrm{~B}$, with a predominantly astrocytic origin, which has been shown to be a robust, independent outcome predictor in TBI. ${ }^{11}$ Neuron-specific enolase (NSE) is a neuronal enriched glycolytic protein and is used in guidelines for cardiac arrest. ${ }^{13}$ Neurofilament-light (NF-L) is one of the main proteins of the neuroaxonal skeleton and is among the most promising biomarkers for disease severity in multiple sclerosis and amyotrophic lateral sclerosis, ${ }^{14}$ as well as in both mild and severe TBI. ${ }^{15,16}$ Serum levels of other brain-enriched proteins that have been suggested to predict outcome of TBI include glial fibrillary acidic protein (GFAP), an astrocytic cytoskeletal protein, ${ }^{17}$ and ubiquitin carboxy-terminal hydrolase-L1 (UCH-L1), a protein enriched in neurons involved in the production of ubiquitin. ${ }^{18}$ GFAP and UCH-L1 in tandem have recently been suggested to aid in screening mild TBI patients to avoid unnecessary CT scans. ${ }^{19}$ Other studied biomarkers include microtubule-associated protein tau, which is predominantly present in neurons and used clinically as a biomarker in Alzheimer's disease, ${ }^{20}$ but also in acute TBI as well as being aggregated in chronic traumatic encephalopathy. ${ }^{21-23}$

Apart from absolute levels, these proteins exhibit different temporal dynamics in serum. ${ }^{6,24}$ In comparison, UCH-L1, S100B, and tau seem to display short effective half-lives (hours) in blood as compared to GFAP and NSE (days), and for NF-L up to several weeks. ${ }^{25,26}$ Another important factor is to what degree a biomarker is brain enriched, given that contribution from extracranial injuries will affect specificity. For instance, S100B can be released from non-cerebral tissues in the early phase after injury, ${ }^{6}$ whereas GFAP and NF-L are virtually restricted to the nervous system. ${ }^{27}$ Collectively, to be able to accurately associate a biomarker concentration with outcome, it is of importance to determine the temporal profile of the biomarkers in relation to timing of injury, as well as to account for extracranial sources.

Previous studies addressing the predictive power of combinations of protein biomarkers have shown mixed results. ${ }^{6,28-31}$ However, many studies have been relatively small in terms of the number of included patients and analyzed markers. Additionally, few studies have adjusted for temporal dynamics and other acknowledged outcome predictors, such as the independent outcome variables in International Mission for Prognosis and Analysis of Clinical Trials in TBI (IMPACT). ${ }^{3}$

We aimed to assess the predictive power of a panel of six candidate TBI markers (S100B, NSE, NF-L, GFAP, UCH-L1, and tau) in serum, both independently and combined, while adjusting for known outcome predictors in a prospective cohort of neurocritical care unit (NCCU) TBI patients. As a secondary aim, we wished to establish the temporal profiles of these biomarkers, covariance between biomarkers, and association with intra- and extracranial injuries, in order to provide better outcome prediction models and understanding of the relative value of these biomarkers.

\section{Methods}

\section{Study design, ethics, and setting}

The data were collected as part of a prospective, observational study. TBI patients, $18-75$ years age and admitted to the NCCU at the Karolinska University Hospital between 2007 and 2013, were enrolled. Ethical approval was provided by the regional ethical board in Stockholm (\#2005/1526/31/2), and consent was provided by next of kin, in line with the Declaration of Helsinki. The study aimed to follow the STROBE statement for cohort studies (Supplementary Document S1).

\section{Traumatic brain injury management}

TBI management at our department has been described in detail in previous studies. ${ }^{6,29}$ In short, we adhere to guidelines similar to that of the Brain Trauma Foundation. ${ }^{32}$ The upper intracranial pressure (ICP) threshold is $20 \mathrm{~mm} \mathrm{Hg}$, and in patients approaching the upper ICP limit, we aim for a cerebral perfusion pressure of $50-70 \mathrm{~mm} \mathrm{Hg}$. In patients with refractory high ICP, barbiturate coma (monitored and limited by burst suppression on electroencephalogram) was induced or decompressive hemicraniectomy was performed.

\section{Definition of admission parameters}

Standard demographic data were acquired from hospital charts, including age and sex. Time of trauma was defined as when the alarm came in to the regional alarm central and was acquired through pre-hospital charts. Glasgow Coma Scale (GCS) at admission to the hospital was used and handled as a continuous, ordinal scale in the analyses as previously suggested. ${ }^{33}$ Pupil reaction to light was assessed at hospital admission and defined as either both reactive, unilaterally unresponsive, or bilaterally unresponsive. Prehospital hypoxia was defined as either an oxygen saturation $<90 \%$, or if saturation was not available if the airway was deemed obstructed at the scene of accident. Pre-hospital hypotension was defined as a systolic blood pressure $<90 \mathrm{~mm} \mathrm{Hg}$. Glucose and hemoglobin sampled at admission to the hospital were acquired. These variables create the foundation, together with CT parameters, of the IMPACT study group's TBI outcome prediction calculator. ${ }^{3}$

Abbreviated Injury Scale (AIS), Injury Severity Score (ISS), and New Injury Severity Score (NISS) were assessed by ISS-trained specialist nurses. ${ }^{34,35}$ Significant extracranial multi-trauma, as per previous definitions, ${ }^{33}$ was noted.

\section{Neuroradiology}

CT scans at admission were assessed using Marshall CT classification, as well as Rotterdam and Stockholm CT score. ${ }^{36-38}$ Because the admission CT was used, all patients with focal mass lesions $\left(>25 \mathrm{~cm}^{3}\right)$ were considered Marshall VI. Any progression of intracranial hemorrhages between the first and second CT scans was noted.

For a subset of patients where the CT scan and/or clinical course suggested presence of diffuse axonal injury (DAI), magnetic resonance imaging (MRI) was performed as per clinical routine. The clinical MRI protocol consisted of echo planar diffusion-, fluid attenuated inversion recovery (FLAIR)-, gradient echo (GRE)-, and $\mathrm{T}_{1^{-}}$and $\mathrm{T}_{2}$-weighted image sequences. Either hemorrhagic and/or non-hemorrhagic DAI was noted.

\section{Clinical outcome}

Long-term functional outcome was assessed using the five-stage Glasgow Outcome Score (GOS), where 1=death, 2=persistent 
vegetative state, $3=$ severe disability (dependent state), $4=$ moderate disability (independent state), and $5=$ recovery (including low-grade disability). ${ }^{39}$ The GOS was assessed prospectively through a qualityof-life questionnaire, including questions from structured GOS interviews, that was sent to the patient at 12 months after injury, or in case these were not returned, it was recorded at visits to the outpatient clinic. The date for GOS assessment was noted.

\section{Blood sampling}

Blood was pragmatically sampled, depending on research staff availability, for NF-L, GFAP, UCH-L1, and tau analyses. These were sampled up to three times during the first 2 weeks, if the patient did not die or was discharged. Serum blood collection tubes where used (yellow cap, clot activator with gel). Sampling was performed by arterial lines and then transported to a local biobank where they stood upright for $30 \mathrm{~min}$ to allow coagulation. Samples where then centrifuged for $15 \mathrm{~min}$ at $2000 \mathrm{~g}$ and aliquoted and stored at $-80^{\circ} \mathrm{C}$.

Blood for analysis of S100B and NSE were drawn twice-daily and sent directly to the Department of Clinical Chemistry at the Karolinska University Hospital, as per clinical routine.

\section{Serum analysis}

Serum GFAP, UCH-L1, NF-L and tau concentrations were measured using the Human Neurology 4-Plex A assay (N4PA) on an HD-1 Single molecule array (Simoa) instrument, according to instructions from the manufacturer (Quanterix, Lexington, MA). Measurements were performed by board-certified laboratory technicians, who were blinded to clinical data, in one round of experiments using one batch of reagents and with baseline and follow-up samples analyzed side by side. In the assay, calibrators were run as duplicates, samples as singlicates, and two internal quality-control plasma samples were run in the beginning and the end of each run. Between-day coefficient of variations (CVs) were $8.8 \%$ at $103 \mathrm{pg} / \mathrm{mL}$ and $8.4 \%$ at $7.4 \mathrm{pg} / \mathrm{mL}$ for NF-L, $11.9 \%$ at $1.2 \mathrm{pg} / \mathrm{mL}$ and $9.7 \%$ at $22.5 \mathrm{pg} / \mathrm{mL}$ for tau, $9.0 \%$ at $72 \mathrm{pg} / \mathrm{mL}$ and $7.3 \%$ at $88 \mathrm{pg} / \mathrm{mL}$ for GFAP, and $33.3 \%$ at $11.4 \mathrm{pg} / \mathrm{mL}$ and $34.0 \%$ at $10.8 \mathrm{pg} / \mathrm{mL}$ for UCH-L1.

All serum S100B samples collected until September 2008 were analyzed at Karolinska University Hospital, Department of Clinical Chemistry, using a quantitative automated luminometric immunoassay (LIAISON-mat S100 system; DiaSorin, Sangtec, Italy). In September 2008, the Department changed to an automatic electrochemiluminescence immunoassay (Elecsys S100B; Roche Diagnostics, Penzberg, Germany). A good correspondence between the two methods has been shown, including internal validation by the Department of Clinical Chemistry, Karolinska University Hospital, Solna, Sweden. ${ }^{6}$ Serum NSE samples were analyzed using an immunoradiometric assay (Liaison; DiaSorin) throughout the whole study at the Karolinska University Hospital, Department of Clinical Chemistry. The detection levels for the LIAISON ranges from $0.04 \mu \mathrm{g} / \mathrm{L}$ for NSE and $0.02 \mu \mathrm{g} / \mathrm{L}$ for $\mathrm{S} 100 \mathrm{~B}$, whereas the Elecsys detects serum S100B levels down to $0.005 \mu \mathrm{g} / \mathrm{L}$. No patient presented with concentrations below detection levels.

\section{Statistical analysis}

Data are presented as median and interquartile range (IQR) for continuous data and grouped for categorical data. Univariate logistic regressions toward different levels of the GOS (proportional odds analysis, using "rms" package in R) were applied to study the predictive ability of admission/IMPACT parameters as well as the protein biomarkers. Similar tests were performed toward different CT severity scores for the biomarkers, as well as linear models, were applicable. Protein biomarkers were also tested versus dif- ferent dichotomizations of outcome, GOS1-3 (unfavorable) versus GOS4-5 (favorable), and GOS1 (dead) versus GOS2-5 (alive).

Nagelkerke's pseudo- $R^{2}$ was used to determine model performance and was bias adjusted for multiple parameters using a bootstrap method. Nagelkerke's pseudo- $R^{2}$ describes performance as between " 0 " and " 1 ," where 1 fully explains the model, akin to explained variance. AUC (area under the curve) ROC (receiver operating characteristics) curves were also used to assess model performances (using the pROC package in R). Step-up, as well as a step-down, multi-variable models were used to examine how the biomarkers added explained variability to the baseline outcome predictors used in the IMPACT calculator. ${ }^{3}$ This was done for unfavorable versus favorable outcome as per IMPACT. A sliding window, assessing a proportional odds analysis of the biomarkers toward the GOS and with bootstrapped confidence intervals, was used to assess the prediction performance of a biomarker over time, after trauma.

The R package "ggplot2" and conditional density plots were used to illustrate biomarker data. ${ }^{40}$ Linear correlations (Spearman) were used to determine cross-correlations between the different protein biomarkers, using peak concentrations so that only 1 patient contributed one time point (visualized with "GGally" package). Principal component analysis (PCA) of the biomarkers was performed using R ("prcomp" package) to explore potential protein interactions. ${ }^{41}$ A loading plot, highlighting potential covariance among the biomarkers in the two first components, was created. The statistical program $\mathrm{R}$ was used in the analyses with the interface $\mathrm{R}$-studio (Boston, MA). ${ }^{42} \mathrm{~A} p$ value of $<0.05$ was considered significant.

\section{Missing data}

All univariate regression models performed were done with unimputed data, excluding missing observations. The multivariable prediction models were performed after multiple imputation (MI; "MICE" package, R), as advocated in the statistical literature and by the IMPACT TBI study group. ${ }^{43,44}$ We applied seven imputed sets of data in our MI, with the imputed data coming from a regression imputation with each imputation drawn from a distribution, retaining uncertainty caused by imputation in analyses toward the dichotomized outcomes. All seven models were checked for consistency, and an average Nagelkerke's pseudo- $R^{2}$ of these seven imputations was reported. Patients that had no corresponding S100B/NSE analyses for the three sampling time points in the multi-variable models had their peak concentrations of S100B and NSE imputed.

\section{Results}

\section{Patient demographics}

A total of 502 NCCU TBI patients were admitted between 2007 and 2013, and of these, 172 had been included in the study. Patients were predominantly male $(76 \%)$ with a median age of 55 years (Table 1). Most patients were unconscious upon admission to the hospital (GCS3-8; 70\%). As per trauma definitions, 28\% had significant extracranial injury and the cohort had a relatively high overall trauma severity, with $86 \%$ of patients having either an AIS of 4 ("severe") or 5 ("critical"), with median ISS of 25 and median NISS of 43, indicating that they had more-severe brain injuries than extracranial injuries (Supplementary Table S1). The 1-year mortality was $13 \%$, and the rate of unfavorable outcome (GOS1-3) was $50 \%$ (Table 1).

\section{Sampling}

In total, 421 samples of GFAP, UCH-L1, tau, and NF-L were available, acquired at median 3,6 , and 9 days after trauma 
Table 1. Patient Demographics

\begin{tabular}{|c|c|c|}
\hline Admission characteristics & Subcategory/units & $\mathrm{n}=172$ patients \\
\hline Sex & Male/female $(\% / \%)$ & $130 / 42(76 / 24)$ \\
\hline Age & Median (IQR) & $55(38-62)$ \\
\hline Scene of accident hypoxia & $\begin{array}{l}\text { Yes } \\
\text { Missing data }\end{array}$ & $\begin{array}{c}29(17 \%) \\
8(5 \%)\end{array}$ \\
\hline Scene of accident hypotension & $\begin{array}{l}\text { Yes } \\
\text { Missing data }\end{array}$ & $\begin{aligned} 3 & (2 \%) \\
43 & (25 \%)\end{aligned}$ \\
\hline Admission GCS & $\begin{array}{l}3-8 \\
9-13 \\
14-15\end{array}$ & $\begin{aligned} & 121(70 \%) \\
& 38(22 \%) \\
& 13(8 \%)\end{aligned}$ \\
\hline Admission pupil responsiveness & $\begin{array}{l}\text { Normal } \\
\text { Unilateral unresponsiveness } \\
\text { Bilateral unresponsiveness } \\
\text { Missing data }\end{array}$ & $\begin{aligned} 125 & (73 \%) \\
18 & (10 \%) \\
24 & (14 \%) \\
5 & (3 \%)\end{aligned}$ \\
\hline Admission hemoglobin & $\begin{array}{l}\mathrm{g} / \mathrm{dL}, \text { median (IQR) } \\
\text { Missing data }\end{array}$ & $\begin{array}{l}136(123-146) \\
7(4 \%)\end{array}$ \\
\hline Admission glucose & $\begin{array}{l}\mathrm{mmol} / \mathrm{L}, \text { median }(\mathrm{IQR}) \\
\text { Missing data }\end{array}$ & $\begin{array}{l}7.9(7.0-9.8) \\
30(17 \%)\end{array}$ \\
\hline \multicolumn{3}{|l|}{ Functional outcome } \\
\hline GOS1 (death) & $n(\%)$ & $21(12 \%)$ \\
\hline GOS2 (vegetative state) & $n(\%)$ & 0 \\
\hline GOS3 (severe disability, dependent state) & $n(\%)$ & $63(37 \%)$ \\
\hline GOS4 (moderate disability, independent state) & $n(\%)$ & $49(28 \%)$ \\
\hline GOS5 (mild or no disability) & $n(\%)$ & $39(23 \%)$ \\
\hline Time from trauma to GOS assessment (living patients) & Days, median (IQR) & $366(343-383)$ \\
\hline
\end{tabular}

Patient demographics for the included patients.

GCS, Glasgow Coma Scale; GOS, Glasgow Outcome Scale; IQR, interquartile range.

(Fig. 1; Supplementary Table S2). All 172 patients had at least one sample, $n=146(85 \%)$ had two samples, and $n=95(55 \%)$ had three samples that could be analyzed. These corresponded with $n=363$ S100B and $n=360$ NSE samples, totaling 2407 biomarker measurements. We primarily choose the peak concentration per patient in our analyses because we believe it to contain the most biologically relevant information, which was, except for NF-L (20\%), almost exclusively the first sample (73-95\%; Supplementary Table S2).

\section{Univariate correlation versus injury severity}

The CT scoring systems were used as surrogate markers for injury severity. In general, S100B and UCH-L1 had the strongest correlations with Stockholm CT scores and exhibited the greatest Nagelkerke's pseudo- $R^{2}$ in models predicting Rotterdam CT scores, as well as to hemorrhagic progression between the first and second CT scan (Table 2; Supplementary Fig. S1A-C). Interestingly, in models predicting extracranial trauma, the first sample acquired for S100B and UCH-L1 displayed significant associations (Table 2), whereas no significance was found for the first sample for the other biomarkers. The other biomarkers were associated, albeit less, with increasing severity on the CT scoring systems. Marshall CT classification had the weakest associations, but a higher Marshall (focal injury) was still significant for all biomarkers except tau and NF-L.

A total of 81 patients had an MRI performed because of suspected DAI injuries, and 41 of these also had diffuse injury (Marshall classification I-IV) on their admission CT scan. In this subgroup, no biomarker was significantly increased in DAI $(n=29)$ versus non-DAI $(n=12)$ patients (Table 2$)$.

\section{Univariate correlations versus outcome}

Among the known IMPACT predictors, only age and glucose levels were significantly correlated to outcome in the logistical regression model (Table 3). Other strong associations in the collected clinical data included progression of hematoma between the first and second CT scan (pseudo- $R^{2}, 0.158$ ), as well as the Stockholm CT score on the initial scan (pseudo- $R^{2}, 0.226$; Table 3).

In the univariate models predicting levels of GOS and mortality, $\mathrm{UCH}-\mathrm{L} 1$ explained the most variation (pseudo- $R^{2}, 0.271$ and 0.342 , respectively). GFAP was slightly better than the other markers in predicting the favorable versus unfavorable GOS outcome dichotomization (pseudo- $R^{2}, 0.217$; S100B pseudo- $R^{2}, 0.213$; Table 3). However, in general, S100B, UCH-L1, tau, and GFAP performed similarly between the outcome representations, whereas peak NSE and NF-L levels performed worse (Table 3; Supplementary Fig. S2).

\section{Protein biomarkers versus outcome over time}

The outcome predictions as observed in the univariate regressions (Table 3) can be better elucidated by visualizing protein concentrations over time in relation to the trauma with stratification according to different levels of GOS (Fig. 2). In general, S100B, NSE, GFAP, UCH-L1, and tau presented with initially high levels that decreased over time, whereas NF-L generally increased over time during the study period (Fig. 2). All biomarkers displaying a good discriminatory capacity in the regression models had distinctly higher levels in the group of patients with unfavorable outcome (Fig. 2A). The best predictive period for all markers, 
Table 2. Associations between Protein Biomarkers and Injury Severity

\begin{tabular}{|c|c|c|c|c|c|c|}
\hline & $S 100 B$ & NSE & GFAP & $U C H-L 1$ & Tau & $N F-L$ \\
\hline \multicolumn{7}{|l|}{ CT parameters (first sample) } \\
\hline $\begin{array}{l}\text { Marshall CT classification } \\
\quad\left(p \text { value, adjusted } R^{2}\right)\end{array}$ & $0.002(0.058)$ & $0.040(0.027)$ & $0.004(0.050)$ & $0.015(0.037)$ & $0.072(\mathrm{NS})$ & $0.982(\mathrm{NS})$ \\
\hline $\begin{array}{l}\text { Rotterdam CT score } \\
\quad\left(p \text { value, adjusted } R^{2}\right)\end{array}$ & $<0.001(0.077)$ & $0.005(0.043)$ & $0.002(0.047)$ & $<0.001(0.092)$ & $<0.001(0.082)$ & 0.078 (NS) \\
\hline $\begin{array}{l}\text { Stockholm CT score } \\
\quad(p \text { value, correlation } \\
\text { coefficient })\end{array}$ & $<0.001(0.298)$ & $0.004(0.210)$ & $0.011(0.179)$ & $<0.001(0.283)$ & $<0.001(0.255)$ & $0.024(0.155)$ \\
\hline $\begin{array}{l}\text { Hemorrhagic progression } \\
\text { between first and second } \\
\text { CT }\left(p \text { value, adjusted } R^{2}\right)\end{array}$ & $<0.001(0.099)$ & $<0.001(0.095)$ & $0.009(0.032)$ & $<0.001(0.116)$ & $<0.001(0.081)$ & $0.003(0.047)$ \\
\hline \multicolumn{7}{|l|}{$\begin{array}{l}\text { MRI subgroup } n=42 \\
\text { (diffuse injury on CT, } \\
\text { peak concentration) }\end{array}$} \\
\hline DAI (yes/no) & $\begin{array}{l}0.059 \text { (negative } \\
\text { correlation) }\end{array}$ & $\begin{array}{l}0.104 \text { (negative } \\
\text { correlation) }\end{array}$ & $\begin{array}{l}0.471 \text { (negative } \\
\text { correlation) }\end{array}$ & $\begin{array}{l}0.104 \text { (negative } \\
\text { correlation) }\end{array}$ & $\begin{array}{l}0.043 \text { (negative } \\
\text { correlation) }\end{array}$ & $\begin{array}{l}0.145 \text { (positive } \\
\text { correlation) }\end{array}$ \\
\hline \multicolumn{7}{|l|}{$\begin{array}{l}\text { Extracranial injury } \\
\quad \text { (first sample) }\end{array}$} \\
\hline $\begin{array}{l}\text { Multi-trauma ( } p \text { value, } \\
\left.\text { adjusted } R^{2}\right)\end{array}$ & $0.002(0.091)$ & $0.169(\mathrm{NS})$ & $0.079(\mathrm{NS})$ & $0.006(0.056)$ & $0.298(\mathrm{NS})$ & $0.861(\mathrm{NS})$ \\
\hline
\end{tabular}

Associations between protein biomarkers and intracranial/extracranial injury. Logistic or linear regression models, where appropriate, were used to performed the analyses. Nagelkerke's pseudo- $R^{2}$ is described if statistically significant $(p<0.05)$. For Stockholm CT scores, linear correlation models were used and correlation coefficients presented.

CT, computerized tomography; DAI, diffuse axonal injury; GFAP, glial fibrillary acidic protein; MRI, magnetic resonance imaging; NF-L, neurofilament-light; NSE, neuron-specific enolase; NS, non-significant; S100B, S100 calcium-binding protein B; UCH-L1, ubiquitin carboxyl-terminal hydrolase-L1.

except NF-L, could be observed within 4-5 days of trauma (Fig. 2B), where the pseudo- $R^{2}$ favorable/unfavorable outcome is approximately $0.300-0.400$ for most proteins. A similar result was noted for mortality and different stages of GOS over time after trauma (Supplementary Table S3; Supplementary Fig. S3).

\section{Multi-variable analysis versus outcome}

By combining the IMPACT outcome predictors age, admission GCS and pupil responsiveness, pre-hospital hypoxia and hypotension, as well as admission hemoglobin and glucose levels together with the Rotterdam CT score, a Nagelkerke's pseudo- $R^{2}$ of 0.285 was reached in predicting favorable/unfavorable outcome (Table 4). ${ }^{3}$ We found a substantial increase in the prediction model if the Stockholm CT score was used instead of Rotterdam for CT injury characteristics, so this model (with a pseudo- $R^{2}$ of 0.375 ) was used as our "Base" model.

Step-up model. Each individual biomarker added significant, independent information to the base model, but only S100B, GFAP, and NF-L significantly. NSE added least, whereas the others added in the vicinity of an additional $0.08-0.09$ pseudo- $R^{2}$ (Table 4). GFAP added marginally more than the others and was therefore used as base for the next step-up. The Base + GFAP model exhibited a pseudo- $R^{2}$ of 0.470 , and adding the other markers revealed that NF-L added the most additional variability to that model, now totaling a pseudo- $R^{2}$ of 0.514 . Adding S100B to that dual-marker model resulted in an additional increase to 0.522 (though a nonsignificantly better model, $p=0.223$ ), which was also the maximum pseudo- $R^{2}$ reached, including all biomarkers.

Additionally, in an exploratory approach, we also tested how well the biomarkers did in a proportional odds model using GOS as an ordinal scale. Here, similarly to what was observed in the uni- variate analyses, the best model contained UCH-L1 and additional independent information was provided by NF-L (Supplementary Table S4).

Step-down model. The step-down model contained all Base variables grouped together as one, as well as the peak concentrations of all the biomarkers. The model left the Base variable together with peak levels of GFAP and NF-L.

In predicting different levels of GOS utilizing a proportional odds model, apart from the Base variable, UCH-L1 remained as the only significant biomarker.

\section{Covariance between the biomarkers}

A cross-correlation matrix revealed that some of the peak serum concentration of the biomarkers had a very strong correlation, especially GFAP, UCH-L1, and tau (correlation-coefficients, 0.830.88; Table 5). S100B, NSE, and NF-L exhibited significant, but lower, cross-correlations, approximately $0.50-0.25$, with NF-L showing the lowest relations to the other markers (Supplementary Fig. S4).

The PCA analysis revealed that the first two components explained around $82 \%$ of the variance of the data (Supplementary Table S5), primarily in the first component, with subsequent components explaining substantially less. The predominantly neuronal proteins (except NSE) UCH-L1 and tau clustered tightly (Fig. 3). The predominantly astrocytic proteins S100B and GFAP clustered together with NSE, whereas the axonal NF-L showed a separate trajectory (Fig. 3).

\section{Discussion}

We here combined six of the most commonly used TBI biomarkers in an extensive prospective cohort of NCCU TBI patients 
Table 3. Univariate Analyses versus Patient Outcome

\begin{tabular}{|c|c|c|c|}
\hline Parameters & $\mathrm{p}$ value & Nagelkerke's pseudo- $\mathrm{R}^{2}$ & $A U C(95 \% C I)$ \\
\hline \multicolumn{4}{|l|}{ Admission } \\
\hline Age & $<0.001$ & 0.191 & $0.733(0.658-0.808)$ \\
\hline GCS at admission & 0.106 & NS & $0.569(0.484-0.654)$ \\
\hline GCS at scene of accident & 0.014 & 0.047 & $0.608(0.524-0.699)$ \\
\hline Pupil responsiveness at admission (as factor) & 0.120 & NS & $0.568(0.501-0.634)$ \\
\hline Hemoglobin levels at admission & 0.061 & NS & $0.578(0.490-0.665)$ \\
\hline Glucose levels at admission & 0.015 & 0.054 & $0.593(0.499-0.688)$ \\
\hline Scene of accident hypoxia & 0.131 & NS & $0.545(0.486-0.603)$ \\
\hline Scene of accident hypotension & 0.565 & NS & $0.492(0.466-0.519)$ \\
\hline \multicolumn{4}{|l|}{ CT scan } \\
\hline Marshall CT classification & 0.622 & NS & $0.512(0.440-0.595)$ \\
\hline Rotterdam CT score & 0.033 & 0.035 & $0.584(0.502-0.666)$ \\
\hline Stockholm CT score & $<0.001$ & 0.226 & $0.742(0.669-0.816)$ \\
\hline Progression of hemorrhage & $<0.001$ & 0.158 & $0.656(0.592-0.721)$ \\
\hline \multicolumn{4}{|l|}{ Trauma scores } \\
\hline Head-AIS & 0.044 & 0.032 & $0.589(0.513-0.666)$ \\
\hline NISS & 0.019 & 0.044 & $0.605(0.517-0.693)$ \\
\hline ISS & 0.110 & NS & $0.562(0.475-0.649)$ \\
\hline Significant multi-trauma & 0.514 & NS & $0.476(0.408-0.544)$ \\
\hline \multicolumn{4}{|c|}{ Biomarkers GOS $1-3$ vs $4-5$ (unfavorable vs. favorable) } \\
\hline S100B peak concentration & $<0.001$ & 0.213 & $0.708(0.630-0.787)$ \\
\hline NSE peak concentration & $<0.001$ & 0.085 & $0.604(0.518-0.690)$ \\
\hline GFAP peak concentration & $<0.001$ & 0.217 & $0.724(0.648-0.800)$ \\
\hline UCH-L1 peak concentration & $<0.001$ & 0.211 & $0.742(0.670-0.815)$ \\
\hline Tau peak concentration & $<0.001$ & 0.162 & $0.708(0.631-0.786)$ \\
\hline NF-L peak concentration & $<0.001$ & 0.154 & $0.699(0.622-0.776)$ \\
\hline \multicolumn{4}{|l|}{$\begin{array}{l}\text { Biomarkers GOS } 1 \text { versus } 3 \text { versus } 4 \text { versus } 5 \\
\text { (proportional odds) }\end{array}$} \\
\hline S100B peak concentration & $<0.001$ & 0.197 & 0.729 \\
\hline NSE peak concentration & $<0.001$ & 0.096 & 0.609 \\
\hline GFAP peak concentration & $<0.001$ & 0.174 & 0.741 \\
\hline UCH-L1 peak concentration & $<0.001$ & 0.271 & 0.749 \\
\hline Tau peak concentration & $<0.001$ & 0.207 & 0.713 \\
\hline NF-L peak concentration & $<0.001$ & 0.101 & 0.639 \\
\hline \multicolumn{4}{|l|}{ Biomarkers GOS 1 versus $2-5$ (dead vs. alive) } \\
\hline S100B peak concentration & $<0.001$ & 0.218 & $0.822(0.720-0.923)$ \\
\hline NSE peak concentration & $<0.001$ & 0.132 & $0.645(0.480-0.810)$ \\
\hline GFAP peak concentration & $<0.001$ & 0.203 & $0.814(0.698-0.930)$ \\
\hline UCH-L1 peak concentration & $<0.001$ & 0.342 & $0.828(0.722-0.933)$ \\
\hline Tau peak concentration & $<0.001$ & 0.273 & $0.787(0.680-0.895)$ \\
\hline NF-L peak concentration & 0.041 & 0.046 & $0.651(0.534-0.767)$ \\
\hline
\end{tabular}

Univariate logistic regression displaying Nagelkerke's pseudo- $R^{2}$ and AUC of admission parameters and biomarker levels versus long-term patient outcome in different dichotomizations. "Admission," "CT scan," and "Trauma score" parameters used the GOS1-3 versus 4-5 (unfavorable vs. favorable) outcome dichotomization. Nagelkerke's pseudo- $R^{2}$ is described if statistically significant $(p<0.05)$. For multi-level receiver operating characteristics (ROC) calculations, only AUC can be presented.

AUC, area under curve; CI, confidence interval; GCS, Glasgow Coma Scale; CT, computerized tomography; AIS, Abbreviated Injury Score; NISS, New Injury Severity Score; ISS, Injury Severity Score; GOS, Glasgow Outcome Scale; NS, non-significant; GFAP, glial fibrillary acidic protein; NF-L, neurofilament-light; NSE, neuron-specific enolase; S100B, S100 calcium-binding protein B; UCH-L1, ubiquitin carboxyl-terminal hydrolase-L1.

and found that biomarker levels do, in comparison to other known outcome predictors in TBI, explain more variability in different outcome prediction models. All biomarkers except NSE provided significant information toward all dichotomizations of outcome in univariate analyses, with GFAP and UCH-L1 being the strongest predictors.

Adjusting for IMPACT variables in a multi-variable analysis, combining GFAP and NF-L provided the best enhancement of performance in predictive models, resulting in a pseudo- $R^{2}$ increase from 0.375 to an impressive 0.522 . Compared to the other markers, the strongest covariances were found between GFAP, UCH-L1, and tau, with correlation coefficients reaching $0.83-0.88$, in turn explaining why these markers presumably did not add independent information in combination. Further, the PCA model revealed clustering of proteins with similar cellular origin and/or temporal profiles, grouping the predominantly neuronal markers tau and UCH-L1 and the astrocytic markers S100B and GFAP as well as the temporally different axonal protein NF-L. Collectively, these findings highlight the strong predictive capabilities of serum protein biomarkers in TBI outcome models and that combination of different markers enhances the precision further.

All markers were associated with severity of TBI, as assessed on admission CT scans, however with different degrees of association depending on type of CT scoring. The best association was found to be with the Stockholm CT score, which includes grading of traumatic subarachnoid hemorrhage specifically. ${ }^{38}$ In contrast, the 


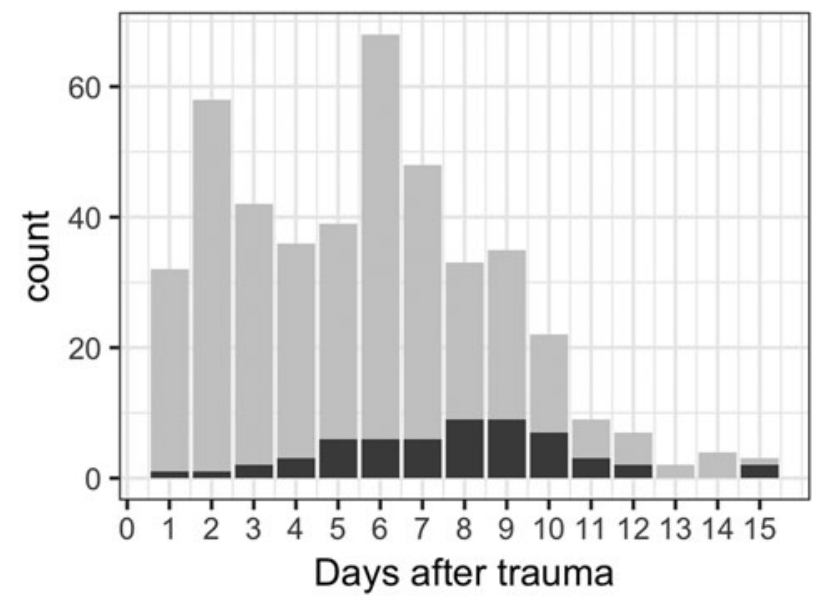

FIG. 1. Sample counts days post-trauma. Counts of samples by day post-trauma (gray, $\mathrm{n}=421$; $\mathrm{x}$-axis, days; $\mathrm{y}$-axis, number of samples [counts]) and counts where exact corresponding times of NSE and S100B did not exist (black, $n=61$ ). NSE, neuron-specific enolase; S100B, S100 calcium-binding protein B.

Rotterdam CT score is more focused on mass-effect components and, perhaps more appropriate, as a marker of affected parenchymal volume,${ }^{37}$ whereas the Marshall CT classification mainly discriminates between diffuse and focal injuries. ${ }^{36}$ None of the markers were significantly associated with DAI detected on MRI. The analyses reached only borderline significance and being lower in patients with DAI (tau $p=0.043$ and S100B $p=0.059$ ), presumably because the non-DAI patients still had had more mixeddensity lesions with greater parenchymal volume affected, though smaller than $25 \mathrm{~cm}^{3}$. The sensitivity for detecting a true difference may be greater if patients with only DAI are selected as done by Ljungqvist and colleagues, where they studied TBI patients with low concentrations of S100B and found that, in this small $(n=9)$ cohort, NF-L levels were associated with extent of DAI injuries on diffusion tensor MRI. ${ }^{45}$

Although being correlated with both TBI severity on admission CT scans and relevant outcomes, early S100B and UCH-L1 levels were also associated with presence of associated non-cranial injuries, replicating previous findings. ${ }^{46-49}$ The other biomarkers displayed limited correlations with extracranial injury, in line with their restricted expression to nervous tissues. ${ }^{27}$ Notably, the temporal sliding window approach used in this study and the relatively few samples in the first $24 \mathrm{~h}$ likely will underestimate the impact of extracranial contribution (Supplementary Fig. S3C). In fact, in a previous study, we found a strong influence of extracranial injuries on S100B and NSE in the first $72 \mathrm{~h}$ with more-frequent sampling in the earlier phases, ${ }^{6}$ when extracranial contribution likely is most important.

All biomarkers used in the study have been previously correlated to outcome in a variety of outcome models. ${ }^{15,28,31,50-64}$ However, unknown timing of injury, measurement of single or a few markers, use of different outcome dichotomizations, and different statistical methods make it practically impossible to say whether one biomarker is superior to another. It is therefore noteworthy that we found individual biomarkers to be better outcome predictors than many other known single predictors, including age, GCS, pupil responsiveness, and most CT scoring systems. Looking specifically at the biomarkers, UCH-L1 performed particularly well against all different outcome dichotomizations used, closely followed by
GFAP, S100B, and tau. In contrast, the predictive values of NF-L and NSE were lower, especially NSE, which could only predict mortality, also in line with work from us and others. ${ }^{6,28}$ It should be noted that NSE levels may be affected by hemolysis of samples, ${ }^{65}$ presumably common in our clinical scenarios. Among the included markers, UCH-L1 has the shortest effective serum half-life (7-10 $\mathrm{h}$ in severe TBI), ${ }^{62}$ which could explain its higher performance, given that a more-severe brain injury will yield a prolonged release.

By visualizing temporal profiles in relation to GOS levels, interesting features of the biomarkers emerge. All biomarkers, except for NF-L, exhibited a decrease in concentration over the first days after injury, leveling at approximately 4 days after trauma. A clear separation of patients that died (GOS1), or had unfavorable outcome (GOS 1-3), can be seen during this time window, indicative of a continued cerebral efflux presumably attributed to ongoing cell death. ${ }^{9}$ This is in line with several previous studies looking at S100B, GFAP, NSE, and UCH-L1, ${ }^{31,59,66,67}$ whereas it has not been reported yet for tau. NF-L clearly stands out among the included markers, given that levels kept increasing throughout the study period, in accord with previous work. ${ }^{15}$

Although previous reports found that UCH-L1 (10 h), tau (10 h), and S100B (24h) have shorter effective half-lives in serum as compared to GFAP (48 h), NSE (48h), and NF-L ( $>1$ weeks) in patients with severe $\mathrm{TBI},{ }^{25,26}$ this is not entirely evident in the current data set. However, it does appear that it takes longer for GFAP to level out as compared to S100B, UCH-L1, and NSE. This is probably also attributed to the low sampling frequency in this study and the subsequently lower resolution of information than in our previous study for S100B and NSE, which observed rather steep declines after $24 \mathrm{~h} .{ }^{6}$ In the present study, NF-L increased over the first 2 weeks, which may relate to a longer effective half-life in serum in addition to release from degeneration of axonal connections with a longer time frame than more-acute necrotic cell death in the impact core. ${ }^{12}$ Thus, NF-L may be more suitable for sampling in more chronic stages of TBI (weeks to months after trauma) and could explain its relatively low predictive power, if used individually, in this study.

More information on the mechanism of efflux of these biomarkers from the cerebral compartment in the context of TBI is also warranted. ${ }^{68}$ It has been speculated that blood-brain barrier (BBB) disruption, ${ }^{69}$ glymphatic system activity independent of BBB disruption, ${ }^{70}$ or a more-passive release from brain/cerebrospinal flu$\mathrm{id}^{71}$ may contribute to efflux. Clearance from serum is also not well described, where only S100B has been studied and has shown a renal clearance. ${ }^{72}$ Other larger proteins are believed to be, at least in part, deaminated and metabolized by the liver, thus also potentially affecting serum levels. ${ }^{73}$ Moreover, they could also be proteolytically processed into smaller fragments no longer recognized by the assays.

GFAP and NF-L added the most independent information when predicting unfavorable outcome in multi-variable models, increasing pseudo- $R^{2}$ from 0.38 to 0.51 . An additional step up with other biomarkers did not significantly improve the models. In theory, adding proteins with different cellular origins or kinetic profiles could contain different information regarding pathophysiological processes, and might be expected to represent the best combination in outcome models.

We have previously noted, for NF-L and S100B, that both markers in combination performed better than either used alone, and that addition of NSE did not provide additional predictive information. ${ }^{6,29}$ Czeiter and colleagues noted, in a study of 45 patients with severe TBI using a more limited IMPACT model 

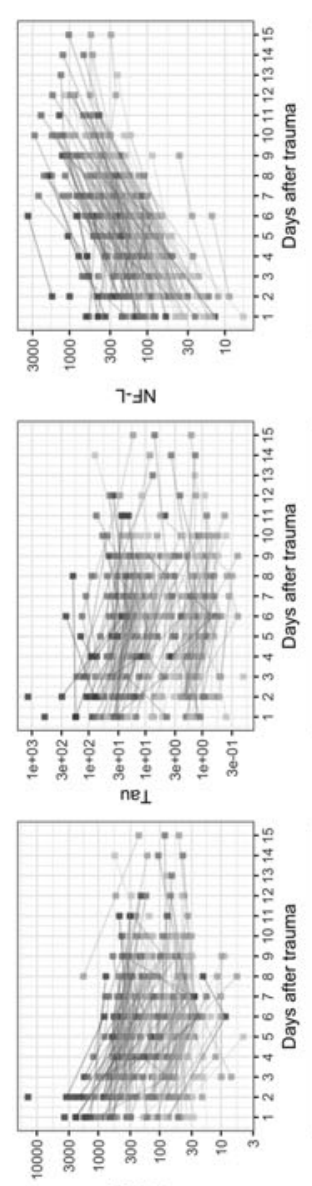

เา.HOก
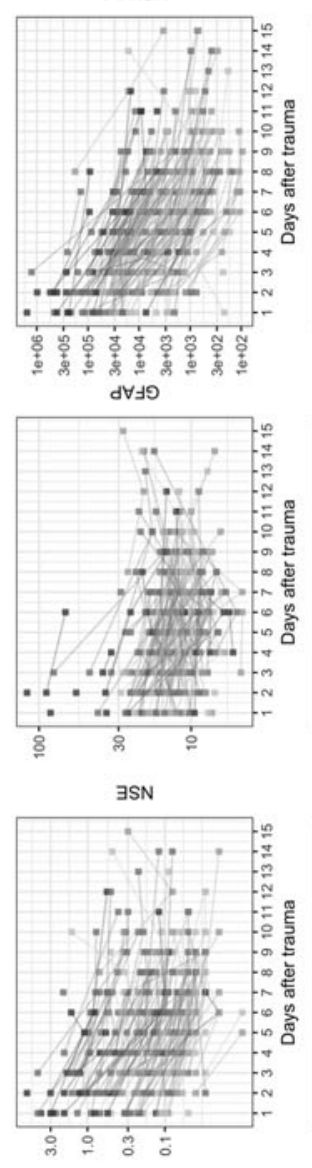

$\varangle \quad 80015$
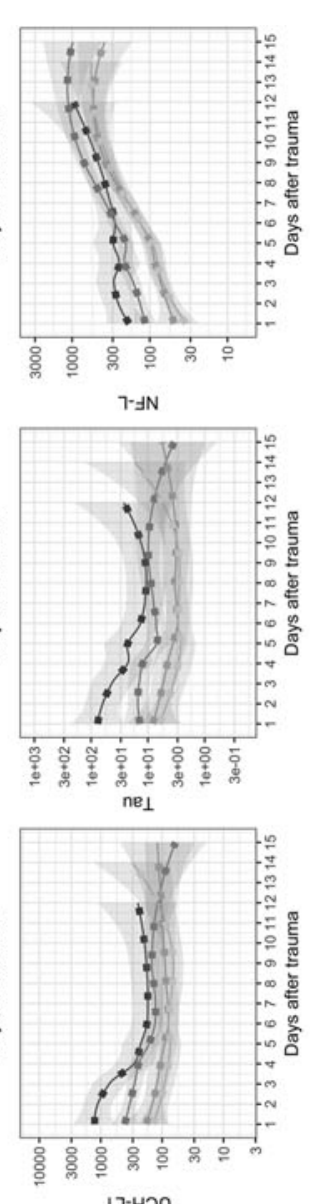

เา-HOก
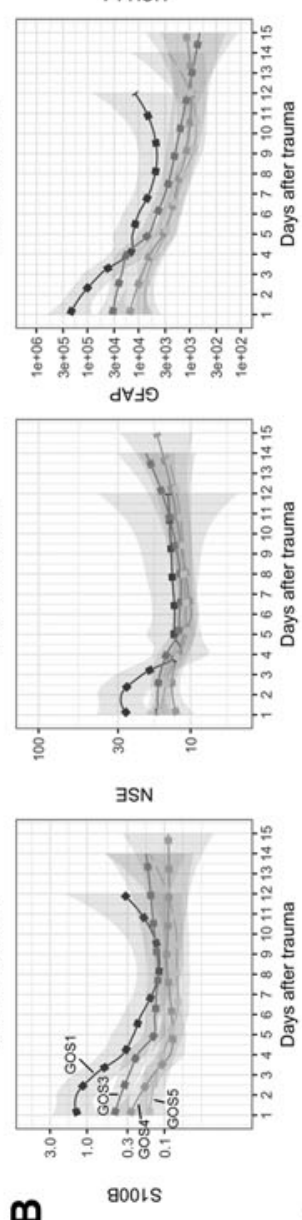
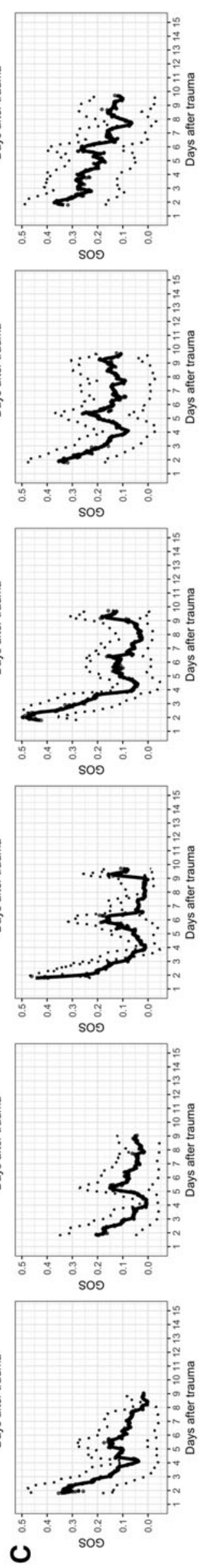

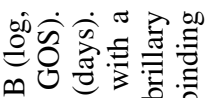

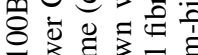

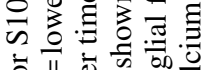

닝.

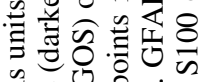

范

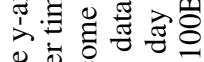

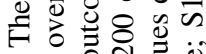

कิ

O

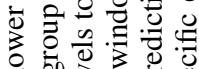

응

可远:

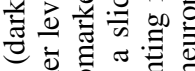

害

응

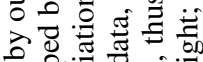

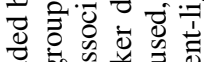

कo 8 ज

no

해의 해음

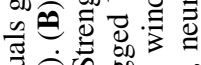

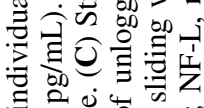

次 0

층

tत

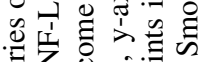

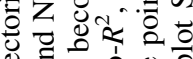

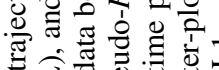

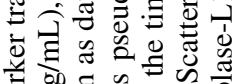

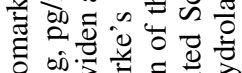

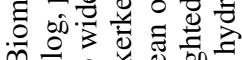

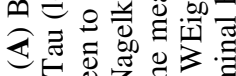

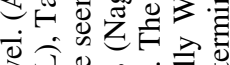

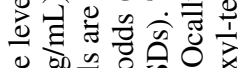

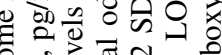

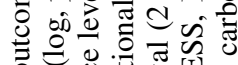

o 0

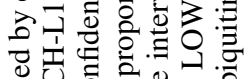

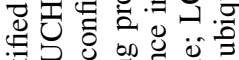

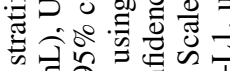

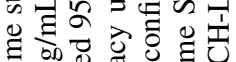

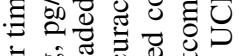

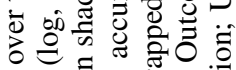
ชै 论

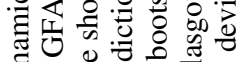

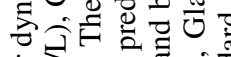

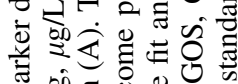

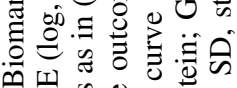

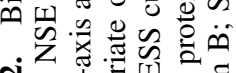

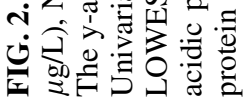


Table 4. Multi-Variable Analyses versus Patient Outcome

\begin{tabular}{lc}
\hline Unfavorable versus favorable outcome & $\begin{array}{c}\text { Nagelkerke's } \\
\text { pseudo- } \mathbf{R}^{2}\end{array}$ \\
\hline IMPACT Rotterdam model & 0.285 \\
Base model (IMPACT but Stockholm & 0.375 \\
CT instead of Rotterdam CT) & \\
Base + S100B & $0.463^{\mathrm{a}}(p=0.003)$ \\
Base + NSE & 0.406 \\
Base + UCH-L1 & 0.458 \\
Base + Tau & 0.445 \\
Base + GFAP & $\mathbf{0 . 4 7 0}(\boldsymbol{p}=\mathbf{0 . 0 1 7})$ \\
Base + NF-L & $0.450^{\mathrm{a}}(p<0.001)$ \\
Base + GFAP + S100B & 0.487 \\
Base + GFAP + NSE & 0.470 \\
Base + GFAP + UCH-L1 & 0.475 \\
Base + GFAP + Tau & 0.479 \\
Base + GFAP + NF-L & $(\boldsymbol{p}=\mathbf{0 . 0 0 1})$ \\
Base + GFAP + NF-L + S100B & $\mathbf{0 . 5 1 4}^{\mathbf{b}}(p=0.223)$ \\
Base + GFAP + NF-L + NSE & 0.514 \\
Base + GFAP + NF-L + UCH-L1 & 0.515 \\
Base + GFAP + NF-L + Tau & 0.514 \\
\hline
\end{tabular}

Multi-variable regression analyses versus unfavorable/favorable (GOS1-3 vs. 4-5) outcome at 12 months. The IMPACT model consists of age, GCS, pupil response, scene of accident hypoxia, scene of accident hypotension, admission glucose, and admission hemoglobin. To this, Rotterdam CT score was added initially, but then replaced by Stockholm CT-score forming the "Base" model used. The model exhibiting highest pseudo- $R^{2}$ is highlighted in bold. Significantly better models according to the likelihood ratio test are shown with $p$ values, stepping up from the nested base model (Base, Base + GFAP or Base + GFAP + NF-L).

${ }^{a}$ Step-up model significantly improved compared to the Base model.

${ }^{\mathrm{b}}$ Step-up model significantly improved compared to Base + GFAP model. $p$ value for Base $+\mathrm{GFAP}+\mathrm{NF}-\mathrm{L}+\mathrm{S} 100 \mathrm{~B}$ highlighted to show that it did not yield independent information over the Base + GFAP + NF-L model.

IMPACT, International Mission for Prognosis and Analysis of Clinical Trials in TBI; CT, computerized tomography; GFAP, glial fibrillary acidic protein; NF-L, neurofilament-light; NSE, neuron-specific enolase; S100B, S100 calcium-binding protein B; UCH-L1, ubiquitin carboxyl-terminal hydrolase-L1.

(a "core" model consisting of only age, GCS motor score, and pupil abnormalities), that GFAP added 0.162 pseudo- $R^{2}$ to this model, ${ }^{30}$ which is, to some extent, similar to our study, but also demonstrates that the other IMPACT and CT parameters retain a lot of the predictive information in these models. Gradisek and colleagues reported similar findings, that is, that S100B and GFAP, but

Table 5. Cross-Correlation Analyses Between DifFERENT Protein Biomarkers

Peak serum levels

S100B NSE GFAP UCH-L1 Tau NF-L

\begin{tabular}{llllllll}
\hline S100B & 1.000 & & & & & \\
NSE & 0.458 & 1.000 & & & & \\
GFAP & 0.670 & 0.496 & 1.000 & & & \\
UCH-L1 & 0.665 & 0.486 & 0.880 & 1.000 & & \\
Tau & 0.632 & 0.548 & 0.824 & 0.877 & 1.000 & \\
NF-L & 0.279 & 0.282 & 0.297 & 0.383 & 0.438 & 1.000
\end{tabular}

Cross-correlation analyses displaying Spearman's rho correlation coefficient for peak serum levels for each patient. This was done in patients where all biomarker levels where present, thus $n=168$.

GFAP, glial fibrillary acidic protein; NF-L, neurofilament-light; NSE, neuron-specific enolase; S100B, S100 calcium-binding protein B; UCHL1, ubiquitin carboxyl-terminal hydrolase-L1.

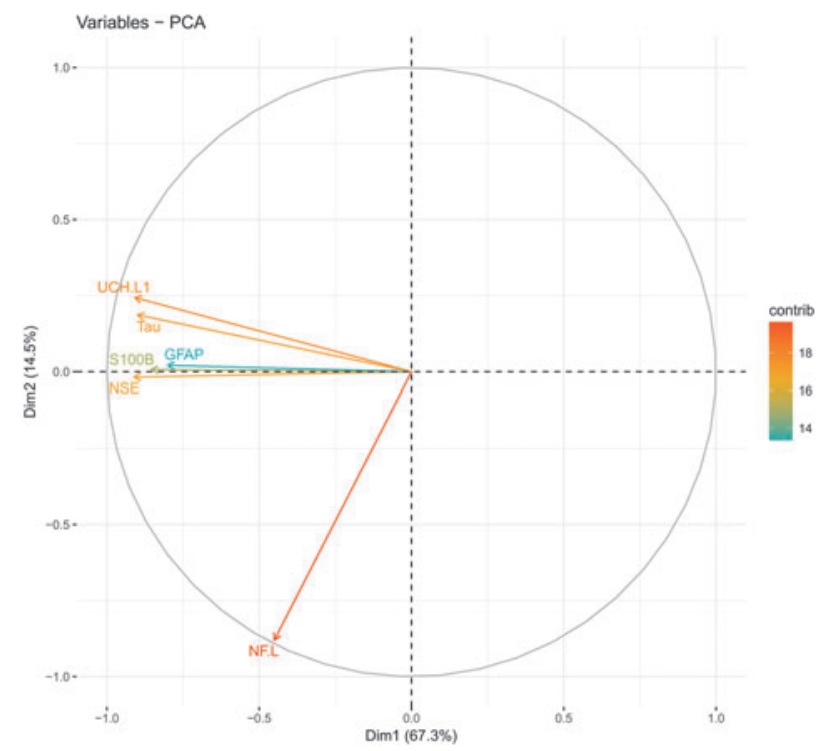

FIG. 3. Principal component analysis of biomarkers. A principal component analysis (PCA) of the first two dimensions of the biomarker data explaining $81.8 \%$ of the data variance. Dimension1 (Dim1, x-axis) explains $67.3 \%$ of the variance and Dim2 (yaxis) an additional $14.5 \%$. The heatmap indicates how well each biomarker is explained (\%) by these two components (vector length). Biomarkers can be seen to have substantial covariance except in the case of NF-L, suggesting it to contain highly different information. GFAP, glial fibrillary acidic protein; NF-L, neurofilament-light; NSE, neuron-specific enolase; S100B, S100 calcium-binding protein B; UCH-L1, ubiquitin carboxyl-terminal hydrolase-L1. Color image is available online.

not NSE, added independent information in outcome prediction models using some admission parameters and CT characteristics predicting mortality, ${ }^{56}$ as was also replicated by Vos and colleagues, where S100B and GFAP performed better in outcome prediction models than if GFAP and NSE were used in the presence of admission parameters. ${ }^{28}$

GFAP, UCH-L1, and tau exhibited strong intercorrelations, with correlations coefficients ranging from 0.83 to 0.88 . Tau levels have not been extensively correlated to other biomarker concentrations, but GFAP and UCH-L1 correlation coefficients have been shown to be 0.24 to approximately $0.50,{ }^{74-79}$ and thus substantially less than in our study. However, these studies mainly included patients with mild TBI, many without intracranial lesions. The study by Korley and colleagues noted in mild TBI that GFAP was slightly better than UCH-L1, NF-L, and tau, but that a model detecting CT positive scans increased from an AUC of 0.88 using GFAP to 0.90 using all the biomarkers together, so a substantial covariance is likely present between markers. ${ }^{79}$ In comparison, TBI patients in need of NCCU care and intracranial monitoring usually suffer from a mix of intra- and extracranial injuries, where biomarker serum release patterns are probably different.

The coefficients observed between S100B, NSE, and other markers in this study are similar to what have been described previously. ${ }^{28,67,74,80}$ NF-L levels did not correlate well with the other markers, especially S100B and NSE, likely because of a difference in the underlying pathophysiology for its release, as well as a potentially different clearance pattern. The PCA revealed a distinct clustering of the primarily neurological markers, tau and UCH-L1, that exhibited similar projections in the first two 
components. The primarily astrocytic markers, S100B and GFAP, also clustered together with the neuronal NSE. In contrast, NF-L with an axonal origin displayed the most unique projection among the markers analyzed here. These findings are in concordance with the multi-variable outcome models and the information content provided by the different biomarkers. The different components probably also indicate different temporal trajectories for the proteins, explaining the very different clustering for NF-L, and why tau and UCH-L1 clustered so closely, as they share temporal patterns.

These findings are difficult to relate to previous work, given that few studies have used this approach before. However, Mondello and colleagues reported on a tentative "glial:neuronal ratio" by creating a ratio between serum levels of GFAP and UCH-L1, ${ }^{81}$ suggesting that patients with more-focal mass lesions on admission CT scans displayed higher GFAP levels, whereas more-diffuse injuries instead released predominantly UCH-L1. In our study, these two markers positioned themselves differently, especially based on the second component, supporting that they might be markers for different underlying pathophysiology (even if not significantly associated with either diffuse or focal injury using Marshall CT, $p=0.359$ data not shown).

In an exploratory analysis, we tested how interactions between biomarkers improved outcome prediction and the only significant biomarkers, if used in a similar ratio, was S100B:GFAP, adding information if S100B and GFAP independently were used in the same outcome prediction model (data not shown). This was presumably attributed to the difference in temporal profiles more than cellular origin. ${ }^{25}$ GFAP was also the protein with least explained variance by the two first principal components, suggesting that it carries different biological information. In summary, the PCA indicated distinct clusters of proteins, supporting that biomarkers of separate cellular origins and temporal profiles may contribute differently in prediction models.

\section{Limitations}

Patients were sampled once to thrice over the first 2 weeks, where more-frequent sampling would have provided more-precise information on temporal profiles. Moreover, the timing of the first sample in relation to injury varied considerably between patients, which likely affected outcome prediction modeling negatively, given that peak values may have been missed. This is specifically limiting for proteins with a shorter effective serum half-life as compared to NF-L.

In cases of milder TBI, GFAP concentrations have been shown to peak at around $24 \mathrm{~h}$, in comparison to UCH-L1, which has a steadier decline. ${ }^{82}$ Presumably, most pathophysiological information is acquired from these "peak" levels, which we have observed in our studies with S100B. ${ }^{11}$ In fact, in an exploratory approach, if the peak levels $12-36 \mathrm{~h}$ after trauma of S100B were used, it outperformed GFAP in the multi-variable outcome prediction models (data not shown), stressing the need to find the ideal time point for each protein. However, the relatively large patient population with non-set-sampling time points may, to some extent, offset these limitations, though the findings presented herein should be replicated by studies with a more-structured sampling procedure, such as CENTER-TBI (Collaborative European NeuroTrauma Effectiveness Research in Traumatic Brain Injury), ${ }^{83}$ which would also allow for external validation our suggested models.

Patients were pragmatically included, depending on the availability of researchers and staff. Thus, though not all NCCU TBI patients were included, we believe the material represents a valid cohort, with more severely injured patients recruited, which is our target population, and that the data are not affected by selection bias.

The lack of a diffuse tensor imaging in our MRI protocol likely underestimated the amount of DAI present in this cohort. However, this method is novel, and GRE (or susceptibility weighted imaging) and FLAIR are still the most commonly used protocols in order to detect different types of DAI today.

Previously, parts of this cohort have been used to analyze NF-L, S100B, and NSE samples and their correlation to outcome in retrospective studies. ${ }^{6,11,29}$ However, for NF-L, a less-sensitive assay was then used and those results were not included in this study. ${ }^{84}$ We believe that inclusion of the clinically implemented S100B and NSE provides a valuable comparison for the more novel markers. It should also be mentioned that none of these newer markers have rapid clinical assays; thus, it takes hours to analyze them, making them yet more difficult to implement for clinical decision making.

We have, in a previous study, meticulously analyzed the effects of the S100B assay change during the study period, but have not been able to show any difference between the samples acquired before, and after, the implementation of the Roche ${ }^{\circledR}$ Cobas ${ }^{\circledR}$ system. ${ }^{6}$ Presumably, this is attributed to the fact that the variation described between these two platforms are primarily observed at higher concentrations than the ones commonly encountered clinically. ${ }^{85}$

We acknowledge that the CT scoring systems used in this article are only surrogate markers for injury severity. Ideally, volumetric maps of the affected brain areas, in order to more accurately quantify the amount of injured brain, should be compared with protein biomarker levels.

The CVs for NF-L, tau, and GFAP were below or around $10 \%$, which is clearly acceptable and well within what is commonly observed in immunoassays. Although CVs for UCH-L1 were higher, it could have made results more uncertain at the individual sample level, even if we believe that this will be balanced at group level considering the amounts of patient included in this study.

\section{Conclusions}

We found that S100B, UCH-L1, GFAP, and tau provided highly significant prediction of GOS and NF-L that of mortality, following TBI. When adjusting for known important predictors of TBI outcome, GFAP and NF-L in combination were found to add the most significant information to multi-variable prediction models. Biomarkers of similar cellular origin and temporal trajectories display strong intercorrelations and similar PCA projections, suggesting why they do not add significant independent information when combined. The combination of different biomarkers, reflecting different cellular origins and pathophysiological processes, significantly improved the prediction models and should represent a valuable tool for improved patient stratification in future TBI trials.

\section{Acknowledgment}

We acknowledge Gunilla Malmborg-Bornhall, RN, for the patient follow-ups and maintaining the trauma database at the neurocritical care unit, Karolinska University Hospital, Stockholm, Sweden.

\section{Author Disclosure Statement/Funding Information}

The funding sources had no role in the design of this study or in its execution, analyses, interpretation of the data, or decision to submit results. 
F.P. has previously received research grants from Biogen, Novartis, and Genzyme and fees for serving as Chair of DMC in clinical trials with Parexel. H.Z. has served at scientific advisory boards of Eli Lilly, Roche Diagnostics, Wave, Samumed, and $\operatorname{CogRx}$; has previously received travel support from Teva; and is a co-founder of Brain Biomarker Solutions in Gothenburg AB, a GU Ventures-based platform company at the University of Gothenburg. K.B. has served as a consultant for or at advisory boards for Alzheon, BioArctic, Biogen, Eli Lilly, Fujirebio Europe, IBL International, Merck, Novartis, Pfizer, and Roche Diagnostics and is a co-founder of Brain Biomarker Solutions in Gothenburg AB.

Support to F.P. for this study was received from the Swedish Research Council (2006-3514-41955-22 and 2009-3514-6883222). Work in the laboratory of H.Z. and K.B. is supported by grants from the Swedish Research Council, the European Research Council, the Knut and Alice Wallenberg Foundation, Hjärnfonden, Alzheimerfonden, and Swedish State Support for Clinical Research (ALFGBG). H.Z. is a Wallenberg Academy Fellow and is additionally supported by the UK Dementia Research Institute at UCL. K.B. holds the Torsten Söderberg Professorship of Medicine. E.P.T. is funded by post-doc scholarships from the Swedish Society for Medical Research and the Swedish Society of Medicine. D.W.N. was supported by funding from the Stockholm County Council.

\section{References}

1. Hyder, A.A., Wunderlich, C.A., Puvanachandra, P., Gururaj, G., and Kobusingye, O.C. (2007). The impact of traumatic brain injuries: a global perspective. NeuroRehabilitation 22, 341-353.

2. Werner, C., and Engelhard, K. (2007). Pathophysiology of traumatic brain injury. Br. J. Anaesth. 99, 4-9.

3. Steyerberg, E.W., Mushkudiani, N., Perel, P., Butcher, I., Lu, J., McHugh, G.S., Murray, G.D., Marmarou, A., Roberts, I., Habbema, J.D., and Maas, A.I. (2008). Predicting outcome after traumatic brain injury: development and international validation of prognostic scores based on admission characteristics. PLoS Med. 5, e165; discussion, e165.

4. Thelin, E.P., Nelson, D.W., Vehvilainen, J., Nystrom, H., Kivisaari, R., Siironen, J., Svensson, M., Skrifvars, M.B., Bellander, B.M., and Raj, R. (2017). Evaluation of novel computerized tomography scoring systems in human traumatic brain injury: an observational, multicenter study. PLoS Med. 14, e1002368.

5. Murray, G.D., Butcher, I., McHugh, G.S., Lu, J., Mushkudiani, N.A., Maas, A.I., Marmarou, A., and Steyerberg, E.W. (2007). Multivariable prognostic analysis in traumatic brain injury: results from the IMPACT study. J. Neurotrauma 24, 329-337.

6. Thelin, E.P., Jeppsson, E., Frostell, A., Svensson, M., Mondello, S., Bellander, B.M., and Nelson, D.W. (2016). Utility of neuron-specific enolase in traumatic brain injury; relations to S100B levels, outcome, and extracranial injury severity. Crit. Care 20, 285.

7. Wang, K.K., Yang, Z., Zhu, T., Shi, Y., Rubenstein, R., Tyndall, J.A., and Manley, G.T. (2018). An update on diagnostic and prognostic biomarkers for traumatic brain injury. Expert Rev. Mol. Diagn. 18, 165-180.

8. Undén, J., Ingebrigtsen, T., and Romner, B. (2013). Scandinavian guidelines for initial management of minimal, mild and moderate head injuries in adults: an evidence and consensus-based update. BMC Med $11,50$.

9. Thelin, E.P., Nelson, D.W., and Bellander, B.M. (2014). Secondary peaks of S100B in serum relate to subsequent radiological pathology in traumatic brain injury. Neurocrit. Care 20, 217-229.

10. Raabe, A., Kopetsch, O., Woszczyk, A., Lang, J., Gerlach, R., Zimmermann, M., and Seifert, V. (2004). S-100B protein as a serum marker of secondary neurological complications in neurocritical care patients. Neurol. Res. 26, 440-445.

11. Thelin, E.P., Johannesson, L., Nelson, D., and Bellander, B.M. (2013). S100B is an important outcome predictor in traumatic brain injury. J. Neurotrauma 30, 519-528.

12. Zetterberg, H., Smith, D.H., and Blennow, K. (2013). Biomarkers of mild traumatic brain injury in cerebrospinal fluid and blood. Nat. Rev. Neurol. 9, 201-210.
13. Stammet, P., Collignon, O., Hassager, C., Wise, M.P., Hovdenes, J., Aneman, A., Horn, J., Devaux, Y., Erlinge, D., Kjaergaard, J., Gasche, Y., Wanscher, M., Cronberg, T., Friberg, H., Wetterslev, J., Pellis, T., Kuiper, M., Gilson, G., and Nielsen, N.; TTM-Trial Investigators. (2015). Neuron-specific enolase as a predictor of death or poor neurological outcome after out-of-hospital cardiac arrest and targeted temperature management at $33^{\circ} \mathrm{C}$ and $36^{\circ} \mathrm{C}$. J. Am. Coll. Cardiol. 65 , 2104-2114.

14. Khalil, M., Teunissen, C.E., Otto, M., Piehl, F., Sormani, M.P., Gattringer, T., Barro, C., Kappos, L., Comabella, M., Fazekas, F., Petzold, A., Blennow, K., Zetterberg, H., and Kuhle, J. (2018). Neurofilaments as biomarkers in neurological disorders. Nat. Rev. Neurol. 14, 577589.

15. Shahim, P., Gren, M., Liman, V., Andreasson, U., Norgren, N., Tegner, Y., Mattsson, N., Andreasen, N., Ost, M., Zetterberg, H., Nellgard, B., and Blennow, K. (2016). Serum neurofilament light protein predicts clinical outcome in traumatic brain injury. Sci. Rep. 6 , 36791.

16. Shahim, P., Zetterberg, H., Tegner, Y., and Blennow, K. (2017). Serum neurofilament light as a biomarker for mild traumatic brain injury in contact sports. Neurology 88, 1788-1794.

17. Pelinka, L.E., Kroepfl, A., Schmidhammer, R., Krenn, M., Buchinger, W., Redl, H., and Raabe, A. (2004). Glial fibrillary acidic protein in serum after traumatic brain injury and multiple trauma. J. Trauma 57, 1006-1012.

18. Mondello, S., Linnet, A., Buki, A., Robicsek, S., Gabrielli, A., Tepas, J., Papa, L., Brophy, G.M., Tortella, F., Hayes, R.L., and Wang, K.K. (2012). Clinical utility of serum levels of ubiquitin C-terminal hydrolase as a biomarker for severe traumatic brain injury. Neurosurgery $70,666-675$

19. Bazarian, J.J., Biberthaler, P., Welch, R.D., Lewis, L.M., Barzo, P., Bogner-Flatz, V., Gunnar Brolinson, P., Buki, A., Chen, J.Y., Christenson, R.H., Hack, D., Huff, J.S., Johar, S., Jordan, J.D., Leidel, B.A., Lindner, T., Ludington, E., Okonkwo, D.O., Ornato, J., Peacock, W.F. Schmidt, K., Tyndall, J.A., Vossough, A., and Jagoda, A.S. (2018). Serum GFAP and UCH-L1 for prediction of absence of intracranial injuries on head CT (ALERT-TBI): a multicentre observational study. Lancet Neurol. 17, 782-789.

20. Blennow, K., and Zetterberg, H. (2018). Biomarkers for Alzheimer disease-current status and prospects for the future. J. Intern. Med. 284, 643-663.

21. Ost, M., Nylen, K., Csajbok, L., Ohrfelt, A.O., Tullberg, M., Wikkelso, C., Nellgard, P., Rosengren, L., Blennow, K., and Nellgard, B. (2006). Initial CSF total tau correlates with 1-year outcome in patients with traumatic brain injury. Neurology 67, 1600-1604.

22. Shahim, P., Tegner, Y., Wilson, D.H., Randall, J., Skillback, T., Pazooki, D., Kallberg, B., Blennow, K., and Zetterberg, H. (2014). Blood biomarkers for brain injury in concussed professional ice hockey players. JAMA Neurol. 71, 684-692.

23. Mez, J., Daneshvar, D.H., Kiernan, P.T., Abdolmohammadi, B., Alvarez, V.E., Huber, B.R., Alosco, M.L., Solomon, T.M., Nowinski, C.J., McHale, L., Cormier, K.A., Kubilus, C.A., Martin, B.M., Murphy, L., Baugh, C.M., Montenigro, P.H., Chaisson, C.E., Tripodis, Y., Kowall, N.W., Weuve, J., McClean, M.D., Cantu, R.C., Goldstein, L.E., Katz, D.I., Stern, R.A., Stein, T.D., and McKee, A.C. (2017). Clinicopathological evaluation of chronic traumatic encephalopathy in players of American football. JAMA 318, 360-370.

24. Ercole, A., Thelin, E.P., Holst, A., Bellander, B.M., and Nelson, D.W (2016). Kinetic modelling of serum S100b after traumatic brain injury. BMC Neurol. 16, 93.

25. Thelin, E.P., Zeiler, F.A., Ercole, A., Mondello, S., Buki, A., Bellander, B.M., Helmy, A., Menon, D.K., and Nelson, D.W. (2017). Serial sampling of serum protein biomarkers for monitoring human traumatic brain injury dynamics: a systematic review. Front. Neurol. 8,300 .

26. Randall, J., Mortberg, E., Provuncher, G.K., Fournier, D.R., Duffy, D.C., Rubertsson, S., Blennow, K., Zetterberg, H., and Wilson, D.H. (2013). Tau proteins in serum predict neurological outcome after hypoxic brain injury from cardiac arrest: results of a pilot study. Resuscitation $84,351-356$.

27. Sjostedt, E., Fagerberg, L., Hallstrom, B.M., Haggmark, A., Mitsios, N., Nilsson, P., Ponten, F., Hokfelt, T., Uhlen, M., and Mulder, J. (2015). Defining the human brain proteome using transcriptomics and antibody-based profiling with a focus on the cerebral cortex. PLoS One 10, e 0130028 
28. Vos, P.E., Lamers, K.J., Hendriks, J.C., van Haaren, M., Beems, T., Zimmerman, C., van Geel, W., de Reus, H., Biert, J., and Verbeek, M.M. (2004). Glial and neuronal proteins in serum predict outcome after severe traumatic brain injury. Neurology 62, 1303-1310.

29. Al Nimer, F., Thelin, E., Nystrom, H., Dring, A.M., Svenningsson, A., Piehl, F., Nelson, D.W., and Bellander, B.M. (2015). Comparative assessment of the prognostic value of biomarkers in traumatic brain injury reveals an independent role for serum levels of neurofilament light. PLoS One 10, e0132177.

30. Czeiter, E., Mondello, S., Kovacs, N., Sandor, J., Gabrielli, A., Schmid, K., Tortella, F., Wang, K.K., Hayes, R.L., Barzo, P., Ezer, E. Doczi, T., and Buki, A. (2012). Brain injury biomarkers may improve the predictive power of the IMPACT outcome calculator. J. Neurotrauma $29,1770-1778$.

31. Mondello, S., Papa, L., Buki, A., Bullock, M.R., Czeiter, E., Tortella, F.C., Wang, K.K., and Hayes, R.L. (2011). Neuronal and glial markers are differently associated with computed tomography findings and outcome in patients with severe traumatic brain injury: a case control study. Crit. Care 15, R156.

32. Brain Trauma Foundation; American Association of Neurological Surgeons; Congress of Neurological Surgeons. (2007). Guidelines for the management of severe traumatic brain injury. J Neurotrauma 24 , Suppl. 1, S1-S106.

33. Perel, P., Arango, M., Clayton, T., Edwards, P., Komolafe, E., Poccock, S., Roberts, I., Shakur, H., Steyerberg, E., and Yutthakasemsunt, S. (2008). Predicting outcome after traumatic brain injury: practical prognostic models based on large cohort of international patients. BMJ 336, 425-429.

34. Greenspan, L., McLellan, B.A., and Greig, H. (1985). Abbreviated Injury Scale and Injury Severity Score: a scoring chart. J. Trauma 25, 60-64.

35. Osler, T., Baker, S.P., and Long, W. (1997). A modification of the injury severity score that both improves accuracy and simplifies scoring. J. Trauma 43, 922-925; discussion, 925-926.

36. Marshall, L.F., Marshall, S.B., Klauber, M.R., Clark, M.V., Eisenberg, H.M., Jane, J.A., Luerssen, T.G., Marmarou, A., and Foulkes, M.A. (1991). A new classification of head-injury based on computerizedtomography. J. Neurosurg. 75, S14-S20.

37. Maas, A.I., Hukkelhoven, C.W., Marshall, L.F., and Steyerberg, E.W. (2005). Prediction of outcome in traumatic brain injury with computed tomographic characteristics: a comparison between the computed tomographic classification and combinations of computed tomographic predictors. Neurosurgery 57, 1173-1182; discussion, 1173-1182.

38. Nelson, D.W., Nystrom, H., MacCallum, R.M., Thornquist, B., Lilja, A., Bellander, B.M., Rudehill, A., Wanecek, M., and Weitzberg, E. (2010). Extended analysis of early computed tomography scans of traumatic brain injured patients and relations to outcome. J. Neurotrauma $27,51-64$.

39. Jennett, B., and Bond, M. (1975). Assessment of outcome after severe brain damage. Lancet 1, 480-484.

40. Wickham, H. (2009). ggplot2: Elegant Graphics for Data Analysis. Springer-Verlag: New York.

41. Eriksson, L., Antti, H., Gottfries, J., Holmes, E., Johansson, E., Lindgren, F., Long, I., Lundstedt, T., Trygg, J., and Wold, S. (2004). Using chemometrics for navigating in the large data sets of genomics, proteomics, and metabonomics (gpm). Anal. Bioanal. Chem. 380, 419-429.

42. R Core Team. (2008). R: a language and environment for statistical computing. R Foundation for Statistical Computing: Vienna, Austria.

43. Marshall, A., Altman, D.G., Royston, P., and Holder, R.L. (2010). Comparison of techniques for handling missing covariate data within prognostic modelling studies: a simulation study. BMC Med. Res. Methodol. 10, 7 .

44. McHugh, G.S., Butcher, I., Steyerberg, E.W., Lu, J., Mushkudiani, N., Marmarou, A., Maas, A.I., and Murray, G.D. (2007). Statistical approaches to the univariate prognostic analysis of the IMPACT database on traumatic brain injury. J. Neurotrauma 24, 251-258.

45. Ljungqvist, J., Zetterberg, H., Mitsis, M., Blennow, K., and Skoglund, T. (2017). Serum neurofilament light protein as a marker for diffuse axonal injury: results from a case series study. J. Neurotrauma 34, 1124-1127.

46. Savola, O., Pyhtinen, J., Leino, T.K., Siitonen, S., Niemela, O., and Hillbom, M. (2004). Effects of head and extracranial injuries on serum protein S100B levels in trauma patients. J. Trauma 56, 1229-1234; discussion, 1234.
47. Korfias, S., Stranjalis, G., Psachoulia, C., Vasiliadis, C., Pitaridis, M., Boviatsis, E., and Sakas, D.E. (2006). Slight and short-lasting increase of serum S-100B protein in extra-cranial trauma. Brain Inj. 20, 867872.

48. Posti, J.P., Hossain, I., Takala, R.S., Liedes, H., Newcombe, V., Outtrim, J., Katila, A.J., Frantzén, J., Ala-Seppälä, H., Coles, J.P., Kyllonen, A., Maanpää, H.R., Tallus, J., Hutchinson, P.J., van Gils, M., Menon, D.K., and Tenovuo, O.; TBIcare Investigators. (2017). Glial fibrillary acidic protein and ubiquitin C-terminal hydrolase-L1 are not specific biomarkers for mild CT-negative traumatic brain injury. J Neurotrauma. Apr 1. doi: 10.1089/neu.2016.4442. [Epub ahead of print]

49. Papa, L., Lewis, L.M., Silvestri, S., Falk, J.L., Giordano, P., Brophy, G.M., Demery, J.A., Liu, M.C., Mo, J., Akinyi, L., Mondello, S., Schmid, K., Robertson, C.S., Tortella, F.C., Hayes, R.L., and Wang, K.K. (2012). Serum levels of ubiquitin C-terminal hydrolase distinguish mild traumatic brain injury from trauma controls and are elevated in mild and moderate traumatic brain injury patients with intracranial lesions and neurosurgical intervention. J. Trauma Acute Care Surg. 72, 1335-1344.

50. Baker, A.J., Rhind, S.G., Morrison, L.J., Black, S., Crnko, N.T., Shek, P.N., and Rizoli, S.B. (2009). Resuscitation with hypertonic salinedextran reduces serum biomarker levels and correlates with outcome in severe traumatic brain injury patients. J. Neurotrauma 26, 1227 1240.

51. Yan, E.B., Satgunaseelan, L., Paul, E., Bye, N., Nguyen, P., Agyapomaa, D., Kossmann, T., Rosenfeld, J.V., and Morganti-Kossmann, M.C. (2014). Post-traumatic hypoxia is associated with prolonged cerebral cytokine production, higher serum biomarker levels, and poor outcome in patients with severe traumatic brain injury. J. Neurotrauma $31,618-629$.

52. Rodriguez-Rodriguez, A., Egea-Guerrero, J.J., Gordillo-Escobar, E., Enamorado-Enamorado, J., Hernandez-Garcia, C., Ruiz de AzuaLopez, Z., Vilches-Arenas, A., Guerrero, J.M., and Murillo-Cabezas, F. (2016). S100B and Neuron-specific enolase as mortality predictors in patients with severe traumatic brain injury. Neurol. Res. 38, 130 137

53. Raabe, A., Grolms, C., and Seifert, V. (1999). Serum markers of brain damage and outcome prediction in patients after severe head injury. Br. J. Neurosurg. 13, 56-59.

54. Bogoslovsky, T., Wilson, D., Chen, Y., Hanlon, D., Gill, J., Jeromin, A., Song, L., Moore, C., Gong, Y., Kenney, K., and Diaz-Arrastia, R. (2017). Increases of plasma levels of glial fibrillary acidic protein, tau, and amyloid beta up to 90 days after traumatic brain injury. J. Neurotrauma 34, 66-73.

55. Di Battista, A.P., Buonora, J.E., Rhind, S.G., Hutchison, M.G., Baker, A.J., Rizoli, S.B., Diaz-Arrastia, R., and Mueller, G.P. (2015). Blood biomarkers in moderate-to-severe traumatic brain injury: potential utility of a multi-marker approach in characterizing outcome. Front. Neurol. 6, 110

56. Gradisek, P., Osredkar, J., Korsic, M., and Kremzar, B. (2012). Multiple indicators model of long-term mortality in traumatic brain injury. Brain Inj. 26, 1472-1481.

57. Lei, J., Gao, G., Feng, J., Jin, Y., Wang, C., Mao, Q., and Jiang, J. (2015). Glial fibrillary acidic protein as a biomarker in severe traumatic brain injury patients: a prospective cohort study. Crit. Care 19, 362.

58. Lumpkins, K.M., Bochicchio, G.V., Keledjian, K., Simard, J.M., McCunn, M., and Scalea, T. (2008). Glial fibrillary acidic protein is highly correlated with brain injury. J. Trauma $65,778-782$; discussion, 782-774.

59. Pelinka, L.E., Kroepfl, A., Leixnering, M., Buchinger, W., Raabe, A., and Redl, H. (2004). GFAP versus S100B in serum after traumatic brain injury: relationship to brain damage and outcome. J. Neurotrauma $21,1553-1561$.

60. Takala, R.S., Posti, J.P., Runtti, H., Newcombe, V.F., Outtrim, J., Katila, A.J., Frantzen, J., Ala-Seppala, H., Kyllonen, A., Maanpaa, H.R., Tallus, J., Hossain, M.I., Coles, J.P., Hutchinson, P., van Gils, M., Menon, D.K., and Tenovuo, O. (2016). Glial fibrillary acidic protein and ubiquitin C-terminal hydrolase-L1 as outcome predictors in traumatic brain injury. World Neurosurg. 87, 8-20.

61. Nylen, K., Ost, M., Csajbok, L.Z., Nilsson, I., Blennow, K., Nellgard, B., and Rosengren, L. (2006). Increased serum-GFAP in patients with severe traumatic brain injury is related to outcome. J. Neurol. Sci. 240, $85-91$. 
62. Brophy, G.M., Mondello, S., Papa, L., Robicsek, S.A., Gabrielli, A., Tepas, J., 3rd, Buki, A., Robertson, C., Tortella, F.C., Hayes, R.L., and Wang, K.K. (2011). Biokinetic analysis of ubiquitin C-terminal hydrolase-L1 (UCH-L1) in severe traumatic brain injury patient biofluids. J. Neurotrauma 28, 861-870.

63. Liliang, P.C., Liang, C.L., Weng, H.C., Lu, K., Wang, K.W., Chen, H.J., and Chuang, J.H. (2010). Tau proteins in serum predict outcome after severe traumatic brain injury. J. Surg. Res. 160, 302-307.

64. Pandey, S., Singh, K., Sharma, V., Pandey, D., Jha, R.P., Rai, S.K., Chauhan, R.S., and Singh, R. (2017). A prospective pilot study on serum cleaved tau protein as a neurological marker in severe traumatic brain injury. Br. J. Neurosurg. 31, 356-363.

65. Gao, F., Harris, D.N., Sapsed-Byrne, S., and Sharp, S. (1997). Neuronespecific enolase and Sangtec 100 assays during cardiac surgery: part III-dose haemolysis affect their accuracy? Perfusion 12, 171-177.

66. Korfias, S., Stranjalis, G., Boviatsis, E., Psachoulia, C., Jullien, G., Gregson, B., Mendelow, A.D., and Sakas, D.E. (2007). Serum S-100B protein monitoring in patients with severe traumatic brain injury. Intensive Care Med. 33, 255-260.

67. Olivecrona, Z., Bobinski, L., and Koskinen, L.O. (2015). Association of ICP, CPP, CT findings and S-100B and NSE in severe traumatic head injury. Prognostic value of the biomarkers. Brain Inj. 29, 446454.

68. Dadas, A., Washington, J., Marchi, N., and Janigro, D. (2016). Improving the clinical management of traumatic brain injury through the pharmacokinetic modeling of peripheral blood biomarkers. Fluids Barriers CNS 13, 21.

69. Kanner, A.A., Marchi, N., Fazio, V., Mayberg, M.R., Koltz, M.T., Siomin, V., Stevens, G.H., Masaryk, T., Aumayr, B., Vogelbaum, M.A., Barnett, G.H., and Janigro, D. (2003). Serum S100beta: a noninvasive marker of blood-brain barrier function and brain lesions. Cancer 97, 2806-2813.

70. Plog, B.A., Dashnaw, M.L., Hitomi, E., Peng, W., Liao, Y., Lou, N., Deane, R., and Nedergaard, M. (2015). Biomarkers of traumatic injury are transported from brain to blood via the glymphatic system. J. Neurosci. 35, 518-526.

71. Kleindienst, A., Schmidt, C., Parsch, H., Emtmann, I., Xu, Y., and Buchfelder, M. (2010). The passage of S100B from brain to blood is not specifically related to the blood-brain barrier integrity. Cardiovasc. Psychiatry Neurol. 2010, 801295.

72. Jonsson, H., Johnsson, P., Hoglund, P., Alling, C., and Blomquist, S. (2000). Elimination of S100B and renal function after cardiac surgery. J. Cardiothorac. Vasc. Anesth. 14, 698-701.

73. Johnsson, P., Blomquist, S., Luhrs, C., Malmkvist, G., Alling, C., Solem, J.O., and Stahl, E. (2000). Neuron-specific enolase increases in plasma during and immediately after extracorporeal circulation. Ann. Thorac. Surg. 69, 750-754.

74. Welch, R.D., Ellis, M., Lewis, L.M., Ayaz, S.I., Mika, V.H., Millis, S., and Papa, L. (2017). Modeling the kinetics of serum glial fibrillary acidic protein, ubiquitin carboxyl-terminal hydrolase-L1, and S100B concentrations in patients with traumatic brain injury. J. Neurotrauma 34, 1957-1971.

75. Lee, J.Y., Lee, C.Y., Kim, H.R., Lee, C.H., Kim, H.W., and Kim, J.H. (2015). A role of serum-based neuronal and glial markers as potential predictors for distinguishing severity and related outcomes in traumatic brain injury. J. Korean Neurosurg. Soc. 58, 93-100.

76. Posti, J.P., Takala, R.S., Runtti, H., Newcombe, V.F., Outtrim, J., Katila, A.J., Frantzen, J., Ala-Seppala, H., Coles, J.P., Hossain, M.I., Kyllonen, A., Maanpaa, H.R., Tallus, J., Hutchinson, P.J., van Gils, M., Menon, D.K., and Tenovuo, O. (2016). The levels of glial fibrillary acidic protein and ubiquitin C-terminal hydrolase-L1 during the first week after a traumatic brain injury: correlations with clinical and imaging findings. Neurosurgery 79, 456-464.

77. Kou, Z., Gattu, R., Kobeissy, F., Welch, R.D., O’Neil, B.J., Woodard, J.L., Ayaz, S.I., Kulek, A., Kas-Shamoun, R., Mika, V., Zuk, C., Tomasello, F., and Mondello, S. (2013). Combining biochemical and imaging markers to improve diagnosis and characterization of mild traumatic brain injury in the acute setting: results from a pilot study. PLoS One 8, e80296.

78. Diaz-Arrastia, R., Wang, K.K., Papa, L., Sorani, M.D., Yue, J.K., Puccio, A.M., McMahon, P.J., Inoue, T., Yuh, E.L., Lingsma, H.F., Maas, A.I., Valadka, A.B., Okonkwo, D.O., and Manley, G.T. (2014) Acute biomarkers of traumatic brain injury: relationship between plasma levels of ubiquitin C-terminal hydrolase-L1 and glial fibrillary acidic protein. J. Neurotrauma 31, 19-25.

79. Korley, F.K., Yue, J.K., Wilson, D., Hrusovsky, K., Diaz-Arrasta, R., Ferguson, A.R., Yuh, E.L., Mukherjee, P., Wang, K.K.W., Valadka, A., Puccio, A., Okonkwo, D.O., and Manley, G. (2018). Performance evaluation of a multiplex assay for simultaneous detection of four clinically relevant TBI biomarkers. J. Neurotrauma. Jul 23. doi: 10.1089/neu.2017.5623. [Epub ahead of print]

80. Bellander, B.M., Olafsson, I.H., Ghatan, P.H., Bro Skejo, H.P., Hansson, L.O., Wanecek, M., and Svensson, M.A. (2011). Secondary insults following traumatic brain injury enhance complement activation in the human brain and release of the tissue damage marker S100B. Acta Neurochir. (Wien) 153, 90-100.

81. Olivecrona, Z., Bobinski, L., and Koskinen, L.O. (2015). Association of ICP, CPP, CT findings and S-100B and NSE in severe traumatic head injury. Prognostic value of the biomarkers. Brain Inj. 29, 446454.

82. Mondello, S., Jeromin, A., Buki, A., Bullock, R., Czeiter, E., Kovacs, N., Barzo, P., Schmid, K., Tortella, F., Wang, K.K., and Hayes, R.L. (2012). Glial neuronal ratio: a novel index for differentiating injury type in patients with severe traumatic brain injury. J. Neurotrauma 29 , 1096-1104.

83. Papa, L., Brophy, G.M., Welch, R.D., Lewis, L.M., Braga, C.F., Tan, C.N., Ameli, N.J., Lopez, M.A., Haeussler, C.A., Mendez Giordano, D.I., Silvestri, S., Giordano, P., Weber, K.D., Hill-Pryor, C., and Hack, D.C. (2016). Time course and diagnostic accuracy of glial and neuronal blood biomarkers GFAP and UCH-L1 in a large cohort of trauma patients with and without mild traumatic brain injury. JAMA Neurol. 73, 551-560.

84. Maas, A.I., Menon, D.K., Steyerberg, E.W., Citerio, G., Lecky, F., Manley, G.T., Hill, S., Legrand, V., and Sorgner, A.; CENTER-TBI Participants and Investigators. (2015). Collaborative European NeuroTrauma Effectiveness Research in Traumatic Brain Injury (CENTER-TBI): a prospective longitudinal observational study. Neurosurgery 76, 67-80.

85. Kuhle, J., Barro, C., Andreasson, U., Derfuss, T., Lindberg, R., Sandelius, A., Liman, V., Norgren, N., Blennow, K., and Zetterberg, H. (2016). Comparison of three analytical platforms for quantification of the neurofilament light chain in blood samples: ELISA, electrochemiluminescence immunoassay and Simoa. Clin. Chem. Lab. Med. 54, 1655-1661.

86. Muller, K., Elverland, A., Romner, B., Waterloo, K., Langbakk, B., Unden, J., and Ingebrigtsen, T. (2006). Analysis of protein S-100B in serum: a methodological study. Clin. Chem. Lab. Med. 44, 11111114

Address correspondence to:

Eric Thelin, $M D, P h D$

Karolinska Universitetssjukhuset Solna

BioClinicum J5:20

Tema Neuro

forskargrupp Svensson S-171 76 Stockholm

Sweden

E-mail: eric.thelin@ki.se 